\title{
Use of citations and status titles in South Algerians' final projects
}

\section{Bachir Bouhania}

Department of English, Faculty of Letters and Languages, University of Adrar, Adrar, Algeria

Email address:

bouhania@yahoo.fr

\section{To cite this article:}

Bachir Bouhania. Use of Citations and Status Titles in South Algerians' Final Projects. International Journal of Language and Linguistics. Special Issue: The Sociolinguistics of a Changing World. Vol. 2, No. 6-2, 2014, pp. 10-14. doi: 10.11648/j.ijll.s.2014020602.13

\begin{abstract}
In a global world where English is the main means of international communication, the use of the latter language variety has positive as well as negative impacts on its learners as a foreign language. Starting from this observation, the present paper/communication describes some methodological drawbacks found in the final projects of fourth year students. In particular, we analyse the use of status titles such as 'doctor-ustaadh-sheikh' as instances of the mix between English standards of referencing and Arabic ones. And last but not least, we consider the frequency of use of Arabic, English, French, and electronic sources as bibliographical citations to objectively measure the ever-increasing impact of the internet on the teaching/learning processes. This small-scale research is based on a corpus made up of 190 final projects submitted for viva voce during the period extending from 1999 to 2011. Though unbalanced, the sample consists of 171 female students and 39 young males from nine different graduation years. A straight result is the significant use of Arabic, English, French, and electronic sources by the girls.
\end{abstract}

Keywords: Academic Writing, Algeria, Arabic, Citations, English, French, Status Titles

\section{Introduction}

English is becoming more and more important at all educational levels, for business transactions and worldwide communication. The students of the department of English are expected to achieve an acceptable mastery of the language both in oral and in written forms. In the latter part, they have to follow and respect the models of writing to attain an effective communicative level and to lend their works credibility and substantiality. Among these models are the standards of referencing which enable the students to successfully present their ideas in their final projects, namely, Mémoires de fin d'études. It does also enable the readers (examiners, students, and supervisors) to check and verify the writers' sources, and follow their argumentation.

This communication concerns itself with academic and educational matters the main focus of which is the students' lack of precise methodological ways for presenting their research, since the module of 'methodology' was not included in the former BA program. In the final projects, one can note several drawbacks, among which the use of academic titles prefixed to the names of the authors. Another remark is that, nowadays, most students resort to use electronic sources for referencing. Although this choice reflects their access to the worldwide web, it does, on the other hand, show that they spend less time reading, analysing, and quoting from books and scientific papers in traditional print. They rather prefer a material ready to copy and paste.

The data are drawn from a number of final projects (i.e.: 190 'Mémoires de fin d'études') presented during a period spanning from 1999 to 2011. The methodology consists of a general survey of the works, in particular to the bibliographical part. Two straight findings are attained: most students use electronic sources more than paper ones. They also make use of academic status titles when using references and citations; as such they do not respect the already established methodological standards of citation and referencing.

\subsection{Theory}

The literature on academic writing purports that the use of in-text and out-text citations is part and parcel of scientific production. However, it is important to note that 'methodology' is not part of the university English curricula, 
and that most undergraduate and even post-graduate students find tremendous problems to deal with methodological issues, among which is the use of citations.

Some students use Arabic standards of referencing in their English written projects as part of a transfer of "discourse organization" (cf. Mohamed-Sayidina, 2010:253) ${ }^{1}$ from L1 to L2 (English). Consciously or unconsciously, they follow Arabic standards when citing articles, books, and from particular authors. From another angle, one may hypothesise that this problem reflects a lack of knowledge of the international referencing conventions such as the (APA, IEEE, MLA, MRHA, etc) as reported by Fadi Al-Khasawneh "Writing references according to certain conventions (APA, IEEE, etc) helps the students to be scholarly writers and trains them in academic integrity."

Another reason may be that the students have an easy access to the internet WebPages and websites from which they draw their theoretical input. Many research studies have been conducted to deal with this new phenomenon (cf. Leu 2002; Coiro 2003; Harwood 2010) whereby foreign as well as second language learners engage in an online versus print environment. Leu (2002) says: "the Internet has entered our classrooms faster than books, television, computers, the telephone, or any other technology for information and communication" (p: 311)

However, the introduction of this new means of electronic access to worldwide information and knowledge brings with it several drawbacks. Among these is speed of reading and cyber-plagiarism. Kurniawan and Zaphiris (2001) came up with a field research in which students were tested as concerns their preferences for reading online texts or traditional print ones. The readers showed that they read more easily the printed materials than the digital ones.

Within the same trend, Murray (2005) conducted a research to show that there is a transfer of traditional literacy to the digital one. Yet, her result proved the contrary, since the students had tremendous problems reading online texts. A fact she explains in the following words: "print literacy does not automatically transfer to digital literacy" (p: viii). ${ }^{3}$

As for cyber-plagiarism or what is known as "copy and paste" (in French "copier-coller"), it stretches from simple and incorrect referencing, i.e.: in-text citations, to the whole stealing of ideas, hypotheses and works. In the case of students, cyber-plagiarism consists mainly in copying passages (paragraphs) and pasting them on their papers without referring to their original writers, neither to the website sources from which they copied them. In other words, cyber-plagiarism is either deliberate or unintentional.

${ }^{1}$ Mohamed-Sayidina, A. 2010. Transfer of L1 Cohesive Devices and Transition Words into L2 Academic Texts: The Case of Arab Students. RELC Journal 41(3): 253-266.

${ }^{2}$ Leu, D.J, Jr.2001. Internet Project: Preparing students for new literacies in a global village [Exploring Literacy on the Internet department]. The Reading Teacher 54(6). Available: http://www.readingonline.org/electronic/elec_index.asp?HREF=/electronic/RT/301 Column/index.html

${ }^{3}$ Murray, J. 2005. Testing Information Literacy Skills (Grades K - 12). Retrieved April 25, 2012, from http://www.big6.com
Plagiarism may be due to several reasons:

-lack of research skills:

Students do not know how to look for information, and if they get it they do not know how to refer to its source.

- Plagiarism and paraphrasing:

As an instance of unintentional plagiarism is the confusion between plagiarism and paraphrasing. Students do not distinguish between paraphrasing and plagiarizing, particularly when they need to tackle technical subjects with unfamiliar words.

-Problems of referencing:

Sometimes this problem arises from the confusion of styles and of standards of referencing, since there are many models. Universities and disciplines do not always use the same type, which adds to the confusion. On the other hand, the students face the obstacle of how to reproduce the electronic addresses, for these may change overnight, or may even disappear from the web.

The present research is based on the postulate that «... what writers and readers do with citations and why-and how such micro-practices link to larger social practices of knowledge construction, circulation, and evaluation globally »(Lillis et al. 2010:113)

\section{Methodology}

The methodology used in this research is based on:

- A BIBLIOMETRIC analysis of electronic sources used in English-written final projects as compared to Arabic, English, and French references.

- A STATISTICAL analysis of out-text (references) citations with a particular attention paid to the frequencies of use throughout the years and by the two sexes (males and females) and, last but not least, by modules.

To come up with the date, the researcher made a survey of 190 final projects found in the university's central library as well as in the department's library.

One noticeable fact is that in 1999, only three memoires were presented as the final project was not obligatory at that time. Now and since it has become compulsory, all students are obliged to write and present their projects. This practice started to take its regular shape since 2005.

We also report that some memoires $(n=21)$ were not considered in the research. Most of them did not have any references, for they were 'exposés' rather than final research projects. Having more than one writer, these papers did not follow any methodology and did not even have bibliographies.

The number of informants and their characteristics are reported in the next table:

\footnotetext{
${ }^{4}$-Lillis, T, A. Hewings, D.Vladimirou, and M.J.Curry. 2010. 'The Geolinguistics of English as an academic lingua franca: citation practices across English-medium national and English-medium international journals.' International Journal of Applied Linguistics 20.1: 111-135.
} 
Table 1. Details of the sample

\begin{tabular}{llll}
\hline Years & Males & Females & Total \\
\hline $1999-2005$ & 0 & 3 & 3 \\
$2005-2006$ & 9 & 29 & 38 \\
$2006-2007$ & 4 & 12 & 16 \\
$2007-2008$ & 6 & 15 & 21 \\
$2008-2009$ & 5 & 53 & 58 \\
$2009-2010$ & 6 & 29 & 35 \\
$2010-2011$ & 10 & 30 & 40 \\
total & 40 & 171 & 211 \\
$\%$ & 18,95 & 81,04 & 100 \\
\hline
\end{tabular}

\section{Use of References and Websites}

Table 2. Overall results for the use of references in final projects

\begin{tabular}{lllllll}
\hline Years & Numbers & $\begin{array}{l}\text { Arabic } \\
\text { refs }\end{array}$ & $\begin{array}{l}\text { English } \\
\text { refs }\end{array}$ & $\begin{array}{l}\text { French } \\
\text { refs }\end{array}$ & Websites & Total \\
\hline $1999-2005$ & 3 & 6 & 6 & 0 & 0 & 12 \\
$2005-2006$ & 15 & 17 & 41 & 4 & 38 & 100 \\
$2006-2007$ & 16 & 21 & 86 & 4 & 57 & 168 \\
$2007-2008$ & 21 & 49 & 84 & 7 & 108 & 248 \\
$2008-2009$ & 58 & 81 & 500 & 18 & 433 & 1032 \\
$2009-2010$ & 35 & 30 & 302 & 10 & 251 & 593 \\
$2010-2011$ & 42 & 74 & 252 & 5 & 242 & 573 \\
Total & 190 & 278 & 1271 & 48 & 1129 & 2726 \\
$\%$ & 100 & 10,19 & 46,62 & 1,76 & 41,41 & 100 \\
\hline
\end{tabular}

As reported in table2, the students have a significant use of Arabic references $(n=278,10.19 \%)$ in their bibliographical citations. A fact which shows that, sometimes, they feel a lack of resources in English. A gap they fill with the most readily available material, i.e.: Arabic-written books, papers and research projects. On the other hand, it also proves that the students resort to sources conveyed in a language they understand and, relatively, use well.

The next remark is that the students do not make use of French-written sources $(n=48,01.76 \%)$. This may be due to their non-mastery of the foreign language, or because of the social pressure of their speech community, which rejects the French language as it represents the former colonisers' means of expression (cf. Bouhania 2008 and 2010). ${ }^{5}$

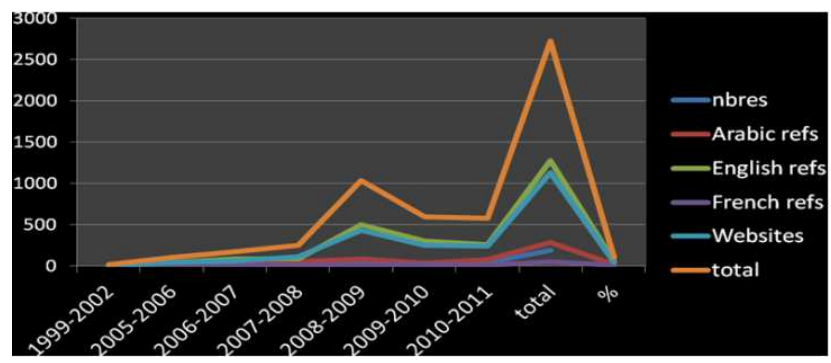

Graph 1. Frequency of use of references

\footnotetext{
5 Bouhania, B. 2008. 'Sociolinguistic Rejection of French by Touat Arabic Speakers: a Post-colonial reaction?' In Lahouel B. (ed.), Africa and the West 4:199-221, University of Oran, Acts of the International conference: Dialogue des Cultures et/ou Culture du dialogue.

-Bouhania, B. 2010. 'Assessing the Ethno-/Sociolinguistic Vitality of 'Arabic', French, and Zenete in the Touat'. Cahiers de Linguistique et Didactique 3:59-83.
}

The third comment is that the students have a strong tendency towards the use of electronic sources $(n=1129$, $41.41 \%)$. Starting from the academic year 2005, the frequency of use of internet sources increased continuously. This is quite noticeable if we compare the 38 WebPages of 2005 to the 242 ones of 2011 , i.e.: $72.49 \%$ of increase!

The next graph reports the overall frequencies of use:

The graph makes it clear that the use of webpages is as important as the use of English references. The other two languages, namely Arabic and French, however, are less frequent.

\subsection{Use of Arabic References}

In the next table, we can note that:

-the girls make use of Arabic references more than the boys, i.e.: $89.77 \%$ vs. $10.22 \%$.

-they also have a very important use of Arabic material sources.

Table 3. Frequency of use of arabic references throughout the years

\begin{tabular}{llll}
\hline years & MALES & FEMALES & Arabic refs. \\
\hline $1999-2002$ & 0 & 6 & 6 \\
$2005-2006$ & 4 & 13 & 17 \\
$2006-2007$ & 0 & 25 & 25 \\
$2007-2008$ & 21 & 10 & 31 \\
$2008-2009$ & 0 & 81 & 81 \\
$2009-2010$ & 0 & 30 & 30 \\
$2010-2011$ & 2 & 72 & 74 \\
Total & 27 & 237 & 264 \\
$\%$ & 10,22 & 89,77 & 100 \\
\hline
\end{tabular}

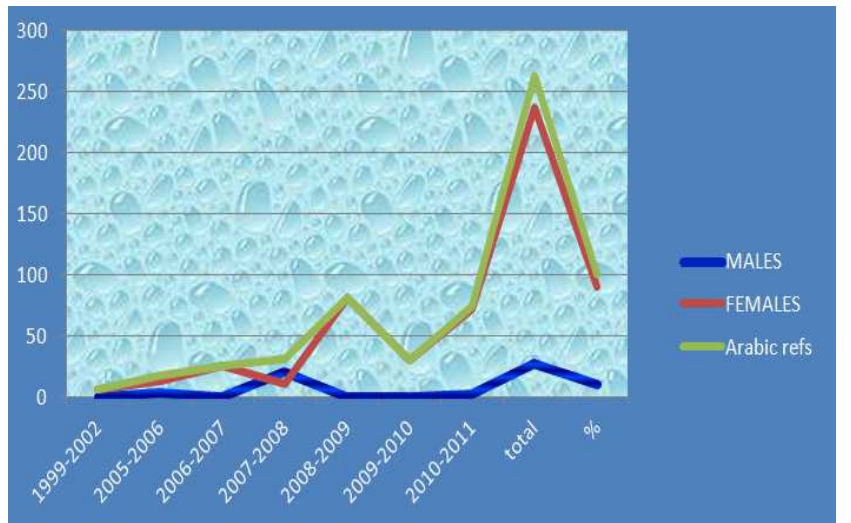

Graph 2. Frequency of use of Arabic references throughout the years

\subsubsection{Use of Arabic References by Seminars}

Table 4. frequency of use of Arabic references by seminars

\begin{tabular}{lllllll}
\hline $\begin{array}{l}\text { Arabic } \\
\text { refs }\end{array}$ & Ling & Civ & Psycho & TEFL & Lit & Total \\
\hline $1999-2005$ & 0 & 3 & 0 & 0 & 0 & 3 \\
$2005-2006$ & 7 & 3 & 1 & 5 & 1 & 17 \\
$2006-2007$ & 16 & 1 & 1 & 1 & 2 & 21 \\
$2007-2008$ & 9 & 15 & 23 & 1 & 1 & 49 \\
$2008-2009$ & 39 & 15 & 30 & 5 & 0 & 89 \\
$2009-2010$ & 28 & 1 & 0 & 1 & 0 & 30 \\
$2010-2011$ & 26 & 37 & 6 & 5 & 0 & 74 \\
Total & 125 & 75 & 61 & 18 & 3 & 283 \\
\hline
\end{tabular}


Graph 3 and table4 show that:

-most Arabic references are used for linguistic projects.

-they are shortly followed by those on civilisation and psychology.

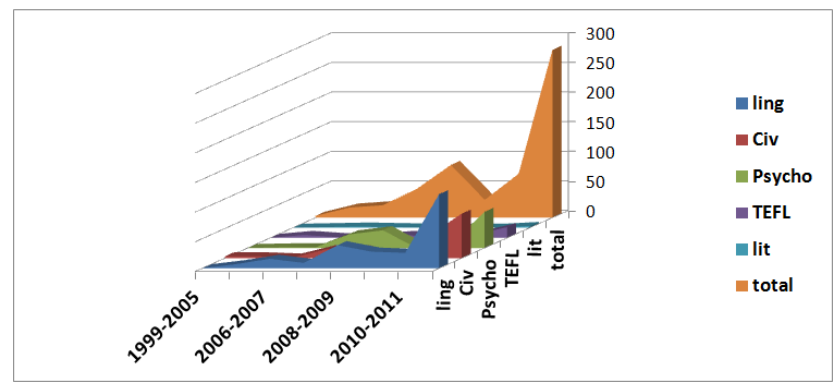

Graph3. Use of Arabic references in various seminars

\subsection{Use of Websites/Webpages}

The table illustrates that:

-The girls, who are more numerous than the boys, have a strong tendency towards the use of the internet web pages in their research, i.e.: $87.86 \%$ vs. $12.13 \%$ for the boys.

-this trend started to become significant from the academic year 2008-2009 onwards.

Table 5. frequency of use of webpages throughout the years

\begin{tabular}{llll}
\hline Years & MALES & FEMALES & Web pages \\
\hline $1999-2002$ & 0 & 0 & 0 \\
$2005-2006$ & 9 & 29 & 38 \\
$2006-2007$ & 0 & 25 & 25 \\
$2007-2008$ & 21 & 45 & 66 \\
$2008-2009$ & 43 & 390 & 433 \\
$2009-2010$ & 21 & 230 & 251 \\
$2010-2011$ & 34 & 208 & 242 \\
total & 128 & 927 & 1055 \\
$\%$ & 12,13 & 87,86 & 100 \\
\hline
\end{tabular}

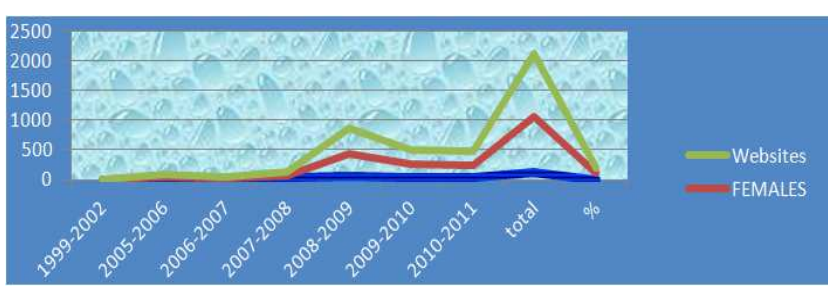

Graph 4. Frequency of use of webpages

\subsection{Use of Webpages by Modules}

Table6. frequency of use of webpages by seminars

\begin{tabular}{lllllll}
\hline Web sites & Ling & Civ & Psycho & TEFL & Lit & total \\
\hline $1999-2005$ & 0 & 0 & 0 & 0 & 0 & 0 \\
$2005-2006$ & 0 & 12 & 2 & 4 & 14 & 32 \\
$2006-2007$ & 12 & 38 & 1 & 3 & 3 & 57 \\
$2007-2008$ & 5 & 59 & 18 & 8 & 18 & 108 \\
$2008-2009$ & 131 & 213 & 60 & 17 & 13 & 434 \\
$2009-2010$ & 77 & 124 & 0 & 47 & 9 & 257 \\
$2010-2011$ & 58 & 98 & 9 & 52 & 25 & 242 \\
total & 283 & 544 & 90 & 131 & 82 & 1130 \\
\hline
\end{tabular}

Table6 and graph5 show that:

-Linguistics, with its various subfields, is the discipline which uses electronic sources the most.

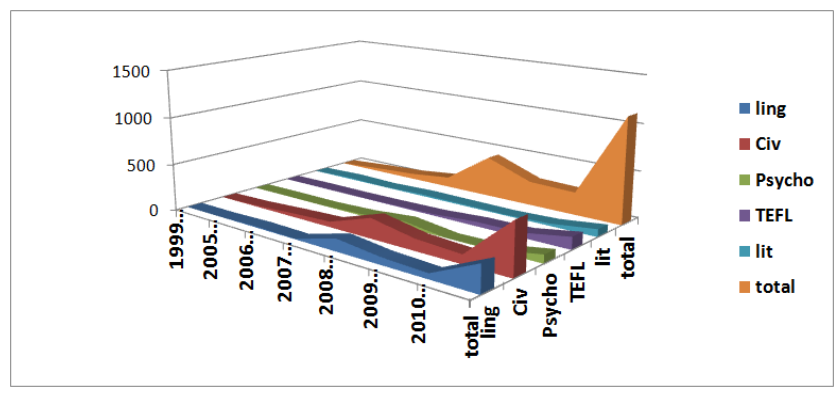

Graph 5. Frequency of use of Arabic references by modules

\subsection{Use of Academic Status Titles}

The students have a noticeable tendency towards the use of academic status titles such as 'doctor', 'ustaadh' and 'sheikh' prefixed to the names of the authors. Most particularly, they employ the abbreviation 'Dr.' in its Arabic form, i.e.: 'د' when citing an Arab writer. However, and it is worth pointing at, they also use the abbreviation in its Latin form when citing authors in the text and outside it. Table 2 gives an overall idea about this phenomenon:

-the use of academic status titles started in 2005-2006 with 'doctor' and 'sheikh'.

-the abbreviation 'Dr.' is the most used $(n=85.71 \%)$; it is shortly followed by 'sheikh' $(\mathrm{n}=12.85 \%)$ in Arabic.

- 2008 and 2009 are the years when the students largely used the status title 'doctor'; the peak being in 2009 with 26 uses.

Table7. use of status titles by students in final projects

\begin{tabular}{llll}
\hline $\begin{array}{l}\text { Academic Status } \\
\text { Titles /Years }\end{array}$ & Doctor & Ustaadh & Sheikh \\
\hline $2005-2006$ & 8 & 0 & 1 \\
$2006-2007$ & 3 & 0 & 2 \\
$2007-2008$ & 16 & 0 & 1 \\
$2008-2009$ & 26 & 1 & 3 \\
$2009-2010$ & 0 & 0 & 2 \\
$2010-2011$ & 7 & 0 & 0 \\
total & 60 & 1 & 9 \\
$\%$ & 85.71 & 1.42 & 12.85 \\
\hline
\end{tabular}

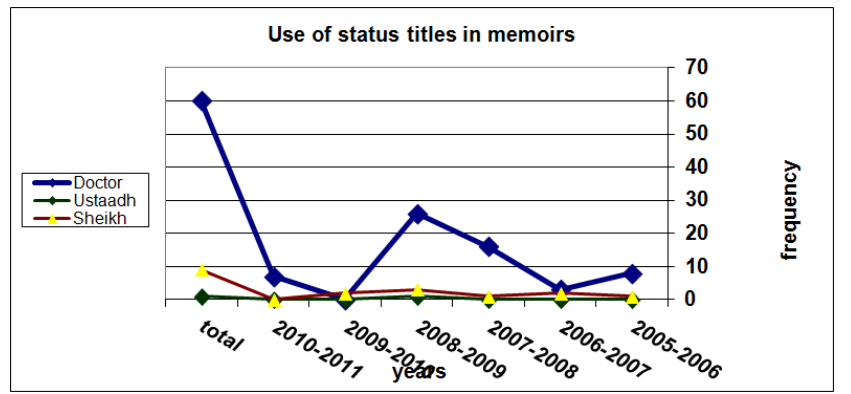

Graph 6. Use of status titles in final projects

\section{Conclusion}

This small-scale research has shown that, most students have some problems in dealing with methodological issues such as citations and references. They mix between the 
standards of references, in particular between Arab and English ones. For instance, they make use of academic status titles prefixed to the authors' names, a fact which contradicts and does not respect the English conventions.

On the other hand, they have a heavy use of Arabic sources in their research projects, particularly in such modules as linguistics and civilisation; this shows that they either do not have the mastery needed to read, comprehend and quote from English written materials, or that they prefer to deal with Arabic written sources which they can understand easily.

The final conclusion is that the lack of "methodology" as a module of teaching is well felt in the students' final projects. This gap makes reading and correcting their 'mémoires' a difficult process.

\section{References}

[1] Bouhania, B. 2008. 'Sociolinguistic Rejection of French by Tuat Arabic Speakers: a Post-colonial reaction?' In Lahouel B. (ed.), Africa and the West $4: 199-221$, U.Oran, Acts of the International conference: Dialogue des Cultures et/ou Culture du dialogue.

[2] Bouhania, B. 2010. 'Assessing the Ethno-/Sociolinguistic Vitality of 'Arabic', French, and Zenete in the Tuat'. Cahiers de Linguistique et Didactique 3:59-83.

[3] Mohamed-Sayidina, A. 2010. Transfer of L1 Cohesive Devices and Transition Words into L2 Academic Texts: The Case of Arab Students. RELC Journal 41(3): 253-266.
[4] Al-Khasawneh, F.M.S. 2010. Writing for Academic Purposes: Problems Faced by Arab Postgraduate Students of the College of Business, Uum. ESP World, Issue 2 (28), Volume 9, http://www.esp-world.info

[5] Harwood, N. 2010. English Language Teaching Materials: Theory and Practice. Cambridge: CUP.

[6] Coiro, J. 2003. Reading comprehension on the Internet: Expending our understanding of reading comprehension to encompass new literacies. The Reading Teacher 56:458-64.

[7] Leu, D.J., Jr. (2001, March). Internet Project: Preparing students for new literacies in a global village [Exploring Literacy on the Internet department]. The Reading Teacher, 54(6). Available: http://www.readingonline.org/electronic/elec_index.asp?HRE $\mathrm{F}=/$ electronic/RT/3-01_Column/index.html

[8] Kurniawan, S.H., \& Zaphiris, P. (2001). "Online or on paper: Which is faster?" [online resource: download April 25, 2012].

[9] Murray, J. (2005). Testing Information Literacy Skills (Grades K - 12). Retrieved April 25, 2012, from http://www.big6.com

[10] Lillis, T, A. Hewings, D.Vladimirou, and M.J.Curry. 2010. 'The Geolinguistics of English as an academic lingua franca: citation practices across English-medium national and English-medium international journals.' International Journal of Applied Linguistics 20.1: 111-135. 